\title{
Red blood cells as an efficient in vitro model for evaluating the efficacy of metallic nanoparticles
}

\author{
Ridhima Wadhwa ${ }^{1} \cdot$ Taru Aggarwal $^{2} \cdot$ Noopur Thapliyal $^{2} \cdot$ Ashutosh Kumar $^{3} \cdot$ Priya $^{4} \cdot$ Pooja Yadav $^{4}$. \\ Vandana Kumari ${ }^{4} \cdot$ Boda Sai Charan Reddy ${ }^{4} \cdot$ Pranjal Chandra ${ }^{3} \cdot$ Pawan Kumar Maurya ${ }^{4}$
}

Received: 29 January 2019 / Accepted: 11 June 2019 / Published online: 21 June 2019

๑) King Abdulaziz City for Science and Technology 2019

\begin{abstract}
Blood and the linings of blood vessels may be regarded as a fifth tissue type. The human body contains $5 \times 10^{9}$ red blood cells (RBCs) per ml, a total of $2.5 \times 10^{13}$ cells in the 51 of blood present in the body. With an average lifetime of 125 days, human RBCs are destroyed by leukocytes in the spleen and liver. Nowadays red blood cells are extensively used to study various metabolic functions. Nanoparticles (NP) are being widely accepted for drug delivery system. This review summarizes the red blood cells, NPs and their characteristics on the basis of the RBC components along with drug delivery systems through RBCs. Further, we also discussed that how erythrocytes can be used as an efficient in vitro model for evaluating the efficacy of various nanocomposite materials.
\end{abstract}

Keywords Red blood cells $\cdot$ Nanoparticles $\cdot$ Drug delivery system $\cdot$ Fabrication

\section{Introduction}

Red blood cells (RBCs) along with its membrane have always been an important medium for the study of various physiological and metabolic aspects (Kumar et al. 2016). Erythrocytes have been increasingly studied because these are the easiest available human cell type. The erythrocytes have been modified by evolutionary forces into a highly specialized tissue that is mainly responsible for providing

Ridhima Wadhwa and Taru Aggarwal have contributed equally to this work.

Pawan Kumar Maurya

pkmaurya@cuh.ac.in

Pranjal Chandra

pchandra13@iitg.ac.in

1 Faculty of Life Science and Biotechnology, South Asian University, Akbar Bhawan, Chanakyapuri, New Delhi 110021, India

2 Amity Institute of Biotechnology, Amity University Uttar Pradesh, Noida 201303, India

3 Department of Biosciences and Bioengineering, Indian Institute of Technology Guwahati, Guwahati, India

4 Department of Biochemistry, Central University of Haryana, Jant-Pali, Mahendergarh District, Haryana 123031, India oxygen to the tissues (oxygen transport from lungs to the tissues) and partly excrete carbon dioxide as waste. RBCs are capable of extreme changes in shape. Due to their flexibility, RBCs can easily squeeze through capillaries, much narrower than their diameter and can recover rapidly to their original shape (Bransky et al. 2006; Skalak and Branemark 1969). A Mature red blood cell is a biconcave disk-shaped with a diameter of size 8 microns, thickness of 2 microns and having an average lifespan of $120 \pm 20$ days. Due to the absence of cell organelles particularly nucleus and mitochondria, RBCs losses its ability to synthesize amino acids and fatty acids. As such RBCs have a limited capacity of metabolism barely enough to survive its lifespan. RBCs are continuously being removed from the circulation and to maintain their adequate number, they are regularly formed in the bone marrow in accordance with their removal by the reticuloendothelial cell (Kumar and Maurya 2014).

RBCs are packed with a special red-colored molecule called hemoglobin $(\mathrm{Hb}) . \mathrm{Hb}$ forms the main intracellular protein of RBCs and constitutes about $33 \%$ of the cell contents (Steck 1974). It has a molecular weight of $68,000 \mathrm{D}$ and constitutes $97 \%$ of the dry weight of an erythrocyte (Waugh and Evans 1979). The main function of hemoglobin is the transportation of oxygen. It picks up oxygen from the areas where oxygen is abundant (lungs) and releases it where the oxygen concentration is low (tissues). In addition to bind 
oxygen, it also binds to carbon dioxide in tissues and carries it to lungs, from where it is removed.

Mature RBCs lose their synthetic capacity due to which they are unable to replace enzymes, repair its membrane and utilize oxygen as a source of energy. RBCs maintain their physiological state through the supply of energy in the form of ATP formed exclusively by the breakdown of glucose (Maurya et al. 2016a). In addition, RBCs also have the capacity for $\mathrm{NAD}^{+} / \mathrm{NADP}^{+}$reduction and glutathione (GSH) synthesis along with the formation of 2,3-diphosphoglycerate (Paglia and Valentine 1967). The formation of GSH enables red blood cells to protect sulphydryl (-SH) group of proteins against oxidation and to trap metallic ions by forming mercaptides (Orlov and Karkouti 2015).

To maintain the deformability characteristics and its physiological properties, RBCs need energy which is supplied in the form of ATP. In mature RBC, ATP, ADP and AMP form the nucleotide pool of which ATP is the major part (Kim et al. 2017). During glycolysis in red blood cells, two molecules of ATP are used up at the hexose level to form phosphorylated compounds. Glucose-6-phosphate from glucose and fructose-6-bisphosphate from fructose-6-phosphate whereas, four molecules of ATP are generated at the triose level two molecules each, during conversion of 2 molecules of 1,3-bisphosphoglycerate to 3-phosphoglycerate and conversion of phosphoenolpyruvate to pyruvate. This net gain of two molecules of ATP provide the energy for RBCs (Kim et al. 2017).

\section{Plasma membrane and its organization}

The cell, unit structure of at issue is separated from the surrounding medium by a limiting boundary which approximates a two-dimensional planer structure around a cell in contact with its environment. The peripheral zone is elaborated as a three-dimensional region including membrane as permeability barriers. The plasma membrane acquires its characteristic shape due to the presence of attachment on its surface, that reaches into the cell and constitutes the cytoskeleton. Commonly, the cells of the higher organisms are bounded by a membrane which is not of uniform structure. The plasma membrane of one face may differ markedly in structure from that of the opposing face of the cell. The biological membranes separate compartments from one another so that a particular biochemical reaction takes place unhindered by other biochemical reactions of other external or internal influences. One of the most remarkable feature attributed to the living organisms is the coordination of its cellular metabolism. A notable feature of living cell is that it is the functioning of transport system located within the plasma membrane that determines the environment upon either side of the membrane.
The selective permeability of the biological membrane is brought about by membrane-bound transport carriers, each of which have an affinity for only a limited group of chemically similar compounds. The carrier enables molecule to be taken up on one side of the membrane, transport it across the membrane as a complex, and release it on the other side. In this way, hydrophilic molecules can penetrate into the lipophilic barriers of the membrane.

The biomembrane is mainly composed of proteins and lipids with a small amount of carbohydrates which are present in association with the proteins as glycoproteins and with the lipids as glycolipids. Various molecular components of the plasma membrane are organized in a unique manner to give rise to a functional membrane. Thermodynamic consideration for the stability of membrane demands that lipid-protein interaction within the membrane must maximize hydrophobic interaction between the non-polar parts and hydrophilic interaction between polar parts. The potential hydrophobic groups are hydrophobic amino acid residues of membrane proteins and polar part of the lipids. The hydrophilic groups are essentially the ions, zwitterions of amino acids and such polar groups of carbohydrates which are present in the lipid and protein component of the membrane.

Various models of membrane ultrastructure and molecular organization were proposed by a number of different authors. Gorter and Grendel (1925) proposed the basic structure of the erythrocytes membrane which was composed of a lipid bilayer consisting of two monolayers of amphipathic lipid molecules. Davson and Danielli (1943) proposed a trilaminar model of the membrane which explained observed resistivity and low interfacial tension. They proposed that the plasma membrane was three-layered structure having a middle lipid bilayer bounded on either side by a continuous layer of globular polar protein. The membrane model proposed by Davson and Danielli was further modified by Robertson (1959), he proposed a trilaminar structure of membrane and suggested that surface proteins were present in a monolayer. Fluid Mosaic Model as proposed by Singer and Nicholson in 1972 appeared to be the most acceptable model as it fulfilled the general criteria for the function of biological membrane. It has taken into account both the wide variation in the molecular size of the protein and various classes of lipids present in the varying proportion in membrane of different species (Singer and Nicolson 1972). The model also explained its hydrophobic structure and selectively permeable properties along with active transport functions and enzyme activities. This model was able to explain the concept of fluid and the dynamic nature of the membrane. According to this model, the lipids exist in the fluid state and the various protein molecules were floating, submerge or traverse all through the phospholipids bilayer from the mosaic of the bilayer. 
The Fluid Mosaic Model carefully distinguished between the peripheral (extrinsic) and integral (intrinsic) protein of the membrane. Extrinsic proteins are those, which are held by membrane generally on their surface by weak non-covalent forces and are not strongly associated with the lipids. They required only mild treatment for their dissociation from the membrane could be dissociated totally from the lipid entity, and in their dissociation state they are readily soluble in neutral aqueous buffers. Intrinsic proteins were usually strongly associated with the lipids even in their isolated state. They required drastic treatment for their separation from the membrane and were usually insoluble in a neutral aqueous buffer. Intrinsic proteins undergo translation diffusion within the membrane, depending on the effective viscosity of lipids unless it is tied down by some specific forces. However, because of their amphipathic structures, the integral proteins maintain their molecular orientation and the degree of intercalation within the membrane while undergoing translational diffusion in the plane of the membrane.

\section{Red blood cell membrane}

$\mathrm{RBC}$ component is surrounded by a limiting membrane that keeps it separate from the extracellular environment. The normal functioning of this membrane is indispensable for the survival of RBCs in blood circulation. A disorder of membrane functions by virtue of its role in determining cell size, shape and deformable characteristics and/or disorder in the normal functioning of the cell membrane properties due to change in its structure or composition or in cell shape, lead to diminished red cell survival. Deformability of the membrane due to ATP depletion or due to changes in the membrane, associated with the hemoglobin has its influence on the deformability and the rheological properties of the cell (Kumar et al. 2018).

The discoid shape of the RBC is determined by the membrane properties and is a consequence of the excess membrane area relative to cell volume and physical forces within the membrane. Although the RBCs are highly deformable and can readily alter their shape in a constant area, at the same time this limiting membrane is highly resistant to dilation there by accounting for the degree of resistance to hypotonic osmotic lysis (Ademiloye et al. 2016). RBCs membrane provides unique cell surfaces for evaluating the effect of nanoparticles observed in the pathophysiological state of various diseases. It acts in the following manner:

1. Involved in the transfer of non-phosphorylated glucose assimilation by small intestine to different tissues and ultimately to the cells of an organism.

2. Dependent on glucose for the maintenance of the homeostatic state by utilizing the ATP generated by substrate-level phosphorylation during anaerobic glycolysis.
3. Possess the ubiquitously occurring membrane-bound cation dependent ATPases that maintain the optimum intracellular and extracellular concentration of $\mathrm{Na}^{+}, \mathrm{K}^{+}$ and $\mathrm{Ca}^{++}$ions in the blood.

\section{Different modes of drug delivery by utilizing RBCs}

For the advancement of pharmaceutical industry, nanoparticles (NP) are being widely accepted for a drug delivery system where the particle size ranges between 10 and $100 \mathrm{~nm}$ in a minimum of one dimension (Toumey 2015). NPs became very popular due to the fact that the nanomaterial properties vary significantly depending on the size and shape of the particle. NP can act as a carrier to deliver the drug molecule successfully and are more reliable due to change in the physical, chemical and biological properties. There are various methods for the preparation of NPs. These particles can be distinguished by preparation methods such as nanoparticle, nanosphere and nanocapsule (Nagavarma et al. 2012).

Polymeric NPs used to deliver drug via intravenous delivery system, had been widely accepted for the drug delivery system. There are several disadvantages of the polymeric NPs in the circulatory system such as short lifetime, vascular defects, and toxicity. It can be used as a system to provide contrast for diagnosis, but not efficient as a drug delivery system.

NP-based drug delivery system increases the release of multiple drugs at a time, solubility of the drug molecule, absorption rate of the drug molecule, improved immune cells disturbance, and administering the release of drugs. The RBCs play a role important in the circulating environment; therefore, it can be a carrier of NP or can inspire a nanoparticle for drug delivery system. RBCs as a carrier of NPs can efficiently transport DNA, proteins, and drugs to the target tissues, cells and organs. The size of the particle in the nanometer helps to increase the membrane permeability and steadiness in the blood stream. NPs can be designed in such a way that they will function like RBCs membrane in the blood stream. RBCs can act as the membrane for NPs for e.g. Hu et al. demonstrated that with the help of hypotonic treatment, RBC's membrane can be isolated. The obtained membrane can be further coated on the Poly(D,L-lactide-coglycolide) (PLGA) which is charged negatively with the help of sonication (Kroll et al. 2016). RBCs can be employed with nanoparticle in different ways, i.e., RBCs as a carrier of NPs and NPs encapsulated in RBC. The different methods of $\mathrm{RBC}$ employment as nanocarriers can also depend on the type of RBC available. The detailed RBC mimics which can be used as nanocarriers are listed in Table 1.

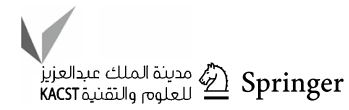




\section{RBCs as a carrier of NP}

Various enzymes and therapeutic agent can not cross the RBCs membrane; therefore the attachment of NPs on the surface of RBC membrane could be employed for efficient delivery of NPs. Anselmo et al. (2013) demonstrated that NP can be adsorbed on the surface of RBCs non-covalently and reversibly suggesting the biocompatibility of NPs and RBC. In some recent studies, improvement in the stream flow was found due to adsorption of NPs on RBC's surface (Pan et al. 2018). Further NPs adsorbed on RBC in the blood circulatory system provide various advantages, such as masking the attached NP, Adsorbed NPs lifetime in the circulatory system is increased, RBCs offer components for making joined compounds by the glycocalyx (Zaitsev et al. 2012) and for load conveyance to vascular targets including thrombi, invulnerable cells, macrophages, endothelial cells, and the RES sinuses (Serafini et al. 2004). The RBCs membrane composed of specific properties which help in the efficient adsorption, for e.g., by utilizing linkers such as erythrocyte-specific surface ligands, avidin-biotin bridge, antigen-antibody binding, carbohydrate moiety oxidized by periodate, or other chemical linkers (Sun et al. 2017). These methods are utilized on the basis of release mechanism at the site due to the sensitivity of target (Fig. 3a).

\section{NPs encapsulated in RBC}

When the NPs are encapsulated inside the RBCs they offer various advantages such as, (1) safeguard the NPs from in vivo interactions with molecules other than target, (2) a significant reduction in the toxic effects of the NP molecules, (3) they provide increased comfortable drug delivery system for patients, and (4) favorable drug release at target only. There are several methods for encapsulation of NP in RBCs such as hypotonic treatment, chemical treatment, electroporation, endocytosis, lipid fusion and membrane-translocating low-molecular weight protamine (He et al. 2014a). Different available strategies are selected on the characterization of $\mathrm{NP}$, therapeutic molecule and release requirements. There are three possible mechanisms underlying the process of RBC loading with NP. In the first one, NPs behave similarly to water-soluble components, reversibly passing through water-flow channels in RBC membrane. This process is mainly driven by the concentration gradient between the exterior and interior of RBCs. In the second process, the incorporation of NP are mediated by membrane proteins and represent the irreversible process of energy-consuming endocytosis. Such NP transport across the membrane takes place when the energy required for penetration through the membrane exceeds the interaction energy between the NPs and the RBC's surface. In the third process, when the appropriate energy is not consumed, the NPs interact preferably 
with the outer layer of membrane proteins, thus preventing their internalization (Fig. 3b).

\section{Drug delivery systems through RBCs}

Drug delivery system (DDS) is defined as the route of administration of a drug or pharmaceutical compound for therapeutic effects. Therefore, DDSs have been classified into three subcategories, i.e., natural (biological), hybrid and artificial. Natural DDSs comprises of the cell and its organelles which are biocompatible and are based on natural mechanisms of transportation, receptivity and localization in body's microenvironment. Hybrid DDSs are a combination of several structural components having a synergistic effect in a therapy. Artificial DDSs are made of natural or synthetic components made of controlled design, material and diversity which are often advantageous over other DDSs.

RBCs fall under the category of natural DDS used in the systemic and vascular transport of pharmaceuticals and probes which can be encapsulated or attached on the surface. The "cargoes" delivery of RBC is characteristic for the delivery in pathological conditions. Transport by RBCs change the pharmacokinetics of a drug through circulation in the blood and re-distributing in cellular components and tissues. This leads to the prolonged effect of drug in the blood, having the potential to act as intravascular therapeutic and thus increases the bioavailability which reduces the dose of drug preventing the side effects. RBCs are effective carrier which regulate blood clotting, transform thrombin, metabolize drugs in blood circulation, bring about endothelium delivery, regulate immunological response and replace deficient lysosomal enzymes.

\section{Synthetic RBC}

The property of RBCs including distinct shape and deformability acts as the basis of mechanobiological characteristics. The physiological properties bring about proper transportation through narrow constrictions, allow the exchange of hemoglobin to enhance oxygen uptake in deep tissues and allow long-term RBC survival in systematic circulation. They are designed to carry hemoglobin that can bind to oxygen (Chen et al. 2012) along with the properties of $\mathrm{pH}$ swelling, modulation and conjugation with small molecules that natural RBCs do not have (Chen et al. 2014). Synthetic RBCs can be derived by layer-by-layer polyelectrolyte particles templating and hydrodynamic jetting which may cause mutations in synthetic RBCs. For instance, PGLA polymer prepared by electrodeposition, natural RBC protein and synthetic polyelectrolyte prepared by layer-by-layer approach over hollow polystyrene sphere leading to dissolution can be used for surface loading and release of heparin and iron oxide nanoparticles (Doshi et al. 2009).

\section{Hybrid RBCs}

To improve the biocompatibility, RBCs components have been used. The exosome like component which have been used to target tumors, not readily accessible to RBCs are known as nanoerythrosomes (LEJEUNE et al. 1994). In vitro studies prove that the nanoerythrosomes are successful prototype to carry loaded cytotoxic agents as anticancer therapy (Désilets et al. 2001). It is also reported that nanoerythrosomes, hybrid RBCs was the successful in delivering anti-malarial agents as compared to free drug in the rat model (Agnihotri et al. 2015).

\section{Fabrication of RBC as a nanocarrier}

\section{Encapsulation of nanoparticle in RBCs}

RBCs are the natural carrier for hemoglobin and hence use inner space for drug delivery (Rizvi and Maurya 2007). Encapsulation process involves isolation of RBCs, loading of drug and infusion into the body for effective delivery and metabolism at the target site. This process involves different surface chemistries, shapes to the surface of RBC and compositions which offers optimal conditions with negligible damage to the RBC with effective drug loading (Sahoo et al. 2017). RBCs do not have internalization pathways which pose a challenge during this process. Therefore, it employs osmotic swelling of RBCs allowing the exchange of drug with hemoglobin on the basis of concentration gradient which is followed by treatment of cells in isotonic solution for resealing the pores. This requires nanoparticle size to be $<100 \mathrm{~nm}$ so that they can enter the cell during osmotic treatment. But, this technology serves drawbacks to the cellular integrity of RBCs due to osmosis and resealing along with biocompatibility of RBCs with the drug molecule. Several enzymes are successfully encapsulated in RBCs those can act on diffusible substrates in blood and serve as a long-term circulating detoxifying agent, therefore, also prevent tumor formation (Magnani et al. 1993). This system is well developed for dexamethasone (Rossi et al. 2001). It is also used to encapsulate inorganic nanoparticles such as iron oxide and gold which can be used for imaging purposes (Antonelli et al. 2011).

To overcome the issue of RBC damage, researchers have started using membrane penetrating peptides (MPPs) for the delivery of drugs using peptides or nanoparticles (Komin et al. 2017). MPPs can destabilize the membrane as they did not contain any organelles and any enzymatic system for membrane repair. Some MPPs accumulate in the membrane

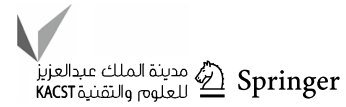


and create pores that are formed comparable by its adjunct. The entrance of MPPs alters the membrane, making it susceptible to physiological and pathological changes that RBCs generally confront while circulation. Majority of MPPs are cationic in nature which may interact with glycocalyx of RBCs thereby, producing undesirable effects such as pro-inflammatory response to endothelium (Villa et al. 2016).

\section{Anchoring NPs on RBCs membrane}

RBCs form a natural circulating system which can be utilized as an efficient delivery system for NPs. The transport of RBC is very efficient due to the fact that RBCs are mediated by several self proteins present on the cell membrane (Hu et al. 2012). For e.g. the self-recognizing markers such as CD47 present on the surface of RBC membrane prevent its disturbance and also activate the signal for macrophages (Tsai et al. 2010). Therefore, if the NPs accumulate the surface properties of RBCs, they can prevent the activation of complementary immune system. In this review, we will be briefing upon the RBC-NPs formation with the help of surface functionalization. NPs can be anchored on the surface of the RBCs with the help of adsorption mechanism (Anselmo et al. 2013). The adsorption of RBCs enable transfer of NP to pulmonary vasculature by not discarding the RBCs carrier (Pan et al. 2018; Anselmo et al. 2013).

The large NP size ranging from $(200-450 \mathrm{~nm})$ can have an enhanced drug delivery system compared to entrapped NPs. The NP rheology in the blood stream can be improved by methods such as non-covalent adhesion on erythrocyte membrane (Chambers and Mitragotri 2004). For the fabrication of NP-RBC complex various methods can be utilized for various nanoparticles:

\section{Polystyrene RBCs complex}

Polystyrene particles modified with carboxyl groups range from $100 \mathrm{~nm}$ to $1.1 \mu \mathrm{m}$ in diameter. First to start with, polystyrene particles were required to be accumulated from the vendor or synthesized prior. Further, the particles can be added to the washed RBCs at a specific RBC ratio ranging from 5:1 to 100:1. The RBCs-NP complex are extracted after centrifugation. These particles readily adhere to RBCs membranes, possibly as a result of non-site specific Van der Waals, electrostatic, hydrogen bonding, and hydrophobic forces between the polystyrene particles and RBCs (Glodek et al. 2010).

\section{NP-RBC complex with the help of surface glycans}

A surface known as glycolyx is present on the surface of RBCs in the form of a dense coating of glycans. This coating of glycans is important for regulating or stopping immune system evasion, also acts as a stabilizer and a good indicator of steadiness of membrane. RBCs membrane is first isolated with the help of hypotonic treatment and sonication. The poly (D, L-lactic-co glycolic acid) (PLGA) polymeric cores are prepared using a $0.67 \mathrm{dL} \mathrm{g}^{-1}$ carboxy-terminated 50: 50 PLGA polymer through a solvent displacement method. The polymer and RBCs membrane is then fused with the PLGA cores, $1 \mathrm{mg}$ of PLGA particles are mixed with RBCs membranes derived and extruded through a $100 \mathrm{~nm}$ polycarbonate porous membrane (Luk et al. 2014). The encapsulation of NPs with the help of PLGA is represented in Fig. 1.

\section{Surface functionalization of AuNP with RBCs}

The functionalizing process of gold NPs with the RBCs membranes consists of two steps (a) membrane vesicles extraction from RBCs (b) Fusing the vesicles onto the surfaces of AuNP. RBCs membrane with the hydrodynamic diameter of approx $100 \mathrm{~nm}$ pores. The fusion is brought by extrusion process enabled from the mechanical stress (Fig. 2).

\section{Applications of RBCs as nanocarriers}

NPs can be utilized as pharmaceutical or in the diagnosis having various advantages due to the change in physicalchemical properties of particle due to variation in the size in nano-range. Various applications of the NP and NP-RBC are listed in Table 2.

\section{Doxorubicin-based RBC-NP}

RBCs membrane-coated NP have been found ideal as they promote evasion of immune system, enhanced resident time and prove appealing for drug delivery for cancer (Hu et al. 2011). The membrane is coated with poly (lactic-co-glycolic acid), a membrane-coated polymeric NPs which makes it biocompatible. This membrane is further loaded with doxorubicin (DOX), a chemotherapeutic drug. A study by Zhang et al. hints upon the immunological response against RBC$\mathrm{NP}$ as an anticancer drug carrier. There is no acute inflammatory response by IL-6, creatinine levels significantly decrease due to increase in activity of kidney to remove free and excess of drug and do not disturb the balance of serum alanine aminotransferase (ALT) and aspartate aminotransferase (AST) level which significantly proves that RBC-NP (DOX) do not affect hepatic activity in mice model (Luk et al. 2016). Repetitive and prolonged administration of RBC-NP (DOX) does not show toxicity and early mortality (Fig. 3). 

particles (NPs) in red blood cell (RBCs).Once the red blood cells (RBCs) are isolated, they are exposed to hypotonic solution to open up the pores on the membrane followed by sonication and extrusion allowing nanoparticles like poly(D,L-lactic-co glycolic acid) (PLGA) to diffuse into the cell before returning the cell to isotonic conditions to seal the pores. These RBCs-NPs have potential to be used for targeted therapy
Fig. 1 Encapsulation of nano-

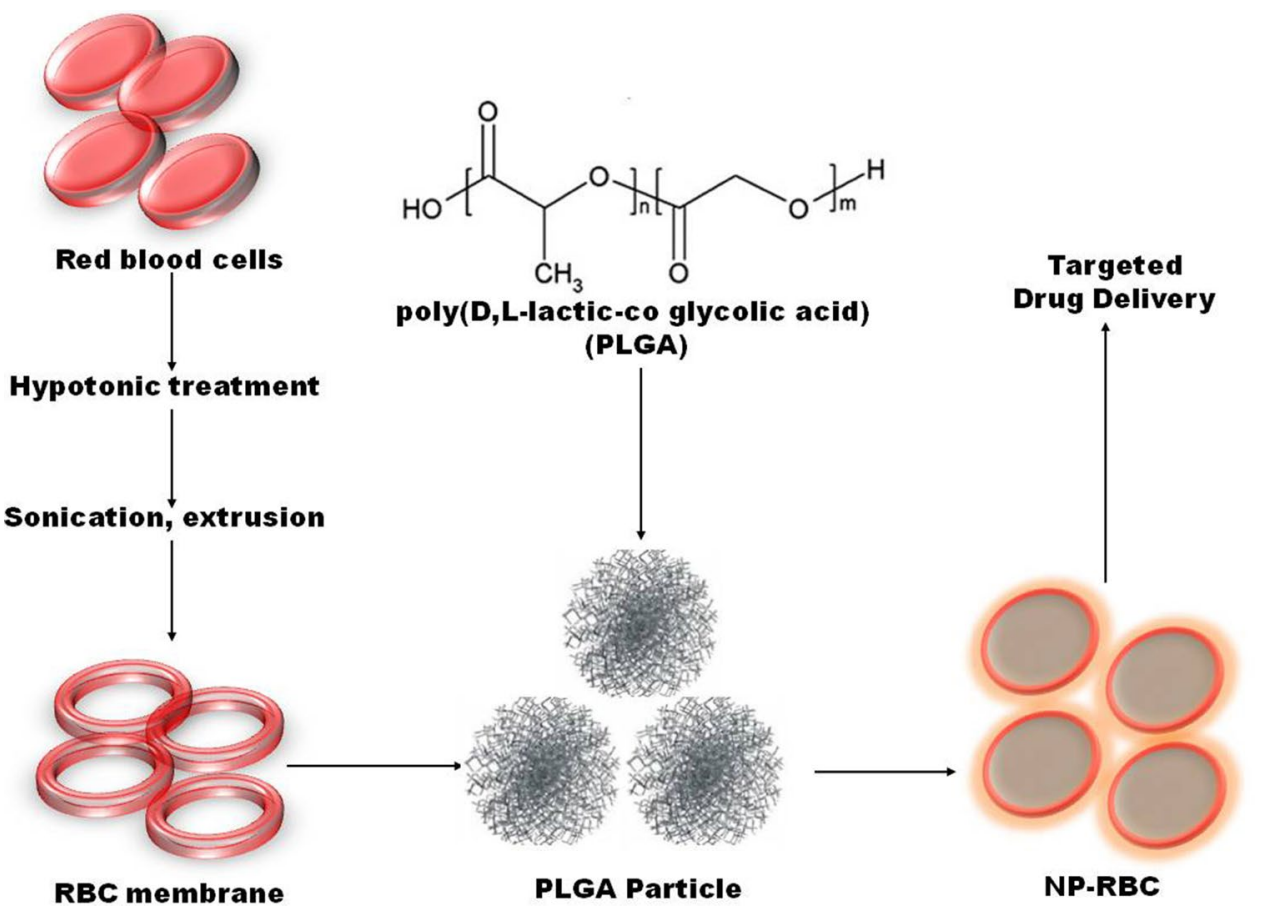

Fig. 2 Induction of oxidative stress by administration of nanoparticles (NPs) in Red blood cells (RBCs). Hemolysis of red blood cells (RBCs) may occur due to binding or encapsulation of nanoparticles. In RBCs, oxidative stress is generated by reactive oxygen species (ROS) and disturbed homeostasis is due to osmotic shock and surface integrity problems. Engineering of nanoparticles (NPs) in RBCs may also encounter autoimmune defense. Therefore, all these factors cumulatively lead to hemolysis of RBCs

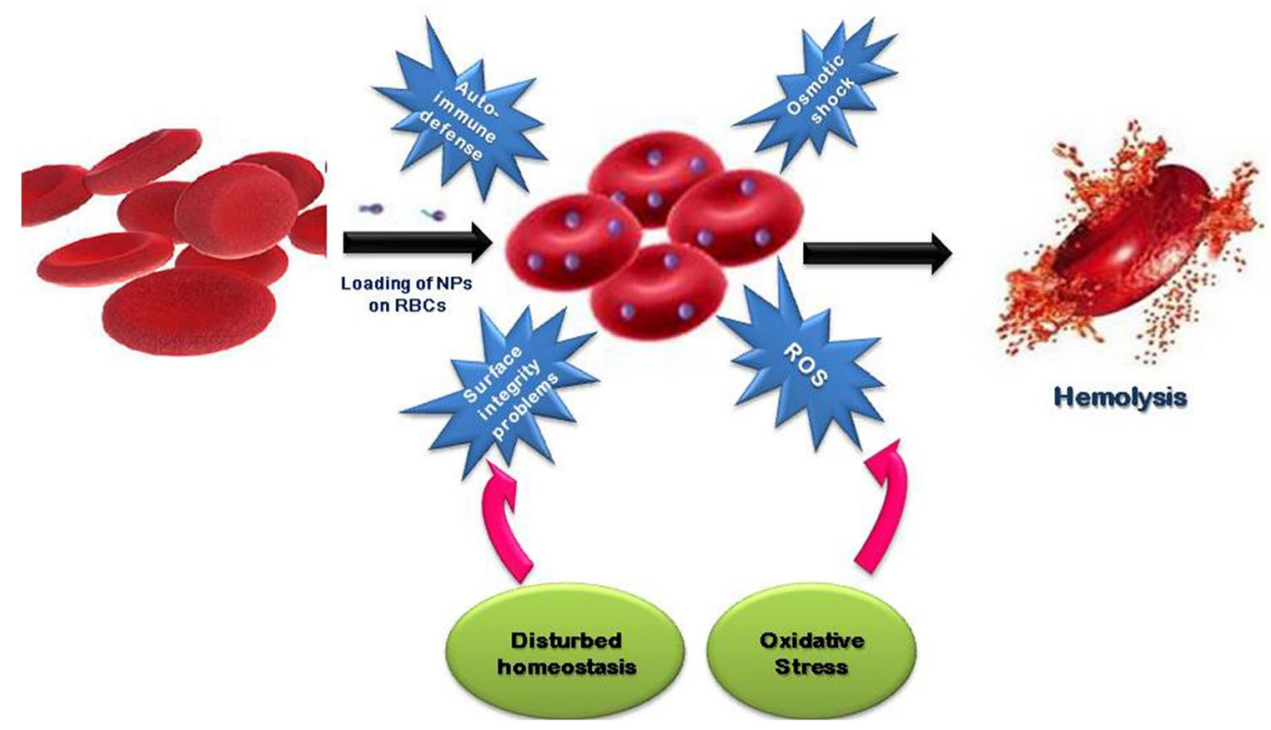

\section{Gold (Au) NP coated on RBCs membrane}

Presence of various modification sites on surface of gold NP allows easy conjugation of AuNP with other molecules and hence making AuNP a desirable candidate for diverse applications. AuNP are widely used as imaging and carrying therapeutics due to versatile properties of biocompatibility, functionalization and optics (Dreaden et al. 2012). Some of the applications include usage in studies for imaging and targeting cancerous cells like A549 (Purohit and Singh 2018) and A431 (Singh 2017) using AuNP coated with glucose which show better result than BSA-AuNPs (Purohit and Singh 2018). Varying surface charges impart catalytic activity to AuNP such as peroxidase, catalase and oxidase activity (Bhagat et al. 2018) which can be used to develop a nanozyme. For example a multi-enzyme Au-CSNPs exhibiting enzymatic activity applied for biosensing (glucose detection) (Bhagat et al. 2018) and some studies have shown that using ATP as a cofactor enhances peroxidase activity of these AuNP (Shah et al. 2015; Shah and Singh 2018).

Due to the long-term circulating property of RBCs, AuNP are functionalized on their surface to make RBCs resistant 
Table 2 Applications of RBC-nanoparticle

\begin{tabular}{|c|c|c|c|c|}
\hline Nanoparticle & Morphology & Target cell type & Application & References \\
\hline $\begin{array}{l}\text { Folate-inserted, red blood } \\
\text { cell membrane-modified } \\
\text { bismuth (F-RBC bismuth) }\end{array}$ & Spherical vesicles & $\begin{array}{l}\text { Human dermal fibroblast } \\
\text { (HDF) } \\
\text { Mouse breast cancer cell line } \\
\quad(4 \mathrm{~T} 1)\end{array}$ & $\begin{array}{l}\text { Effective and safe radio sen- } \\
\text { sitizer for next-generation } \\
\text { X-ray radiation treatment of } \\
\text { cancer }\end{array}$ & Rao et al. (2017) \\
\hline $\begin{array}{l}\text { Hemoglobin }(\mathrm{Hb}) \text {-loaded } \\
\text { mesoporous silica nanopar- } \\
\text { ticles (MSNs) }\end{array}$ & Disk-shaped mesochannels & $\begin{array}{l}\text { Zebrafish (Danio rerio) } \\
\text { embryos }\end{array}$ & $\begin{array}{l}\text { Immune evasion and a long } \\
\text { circulation time }\end{array}$ & Deng et al. (2018) \\
\hline $\begin{array}{l}\text { Erythrocyte membrane-cam- } \\
\text { ouflaged PLGA nanoparti- } \\
\text { cles (MNP) }\end{array}$ & Spherical vesicles & Canpan-2 cells & $\begin{array}{l}\text { Enhance tumor drug delivery } \\
\text { in pancreatic ductal adeno- } \\
\text { carcinoma }\end{array}$ & Tu et al. (2018) \\
\hline $\begin{array}{l}\text { Magnetic mesoporous silica } \\
\text { nanoparticle (MMSN) with } \\
\text { RBC cloaking }\end{array}$ & Spherical & HeLa cells & $\begin{array}{l}\text { Avoid the immune clearance, } \\
\text { and achieve magnetic field } \\
(\mathrm{MF}) \text { induced high-accumu- } \\
\text { lation in tumor. }\end{array}$ & Jiang et al. (2018b) \\
\hline Silicon nanoparticles (SiNPs) & Biconcave shape & U87MG cancer cells & $\begin{array}{l}\text { Tumor imaging and chemo- } \\
\text { therapy }\end{array}$ & Xuan et al. (2018) \\
\hline RBC(M(TPC-PTX)) & Irregular shaped & Hela cells & $\begin{array}{l}\text { Synergistic Photodynamic/ } \\
\text { chemotherapy }\end{array}$ & Jiang et al. (2018a) \\
\hline HSA nanoparticles & Spherical shape & Hela, CT-26 and RAW 264.7 & $\begin{array}{l}\text { Long circulation and } \\
\text { enhanced phototherapy }\end{array}$ & Pei et al. (2018) \\
\hline $\mathrm{Fe}_{3} \mathrm{O}_{4}$ magnetic nanoparticles & Not known & Circulatory system cells & Cancer diagnosis and therapy & Ren et al. (2017) \\
\hline $\begin{array}{l}\text { Mesoporous silica nanoparti- } \\
\text { cles (MSNs), }\end{array}$ & Radial pore & 4T1 breast cancer cells & Tumor-specific drug release & Su et al. (2017) \\
\hline Polypyrrole nanoparticles & & hct 116 cells & $\begin{array}{l}\text { Enhanced photothermal } \\
\text { therapy }\end{array}$ & Wang et al. (2017) \\
\hline
\end{tabular}

Fig. 3 Different modes of drug delivery by utilizing RBC: a represent RBC as carrier of NP, where NP binds to the surface of RBC for targeted drug delivery. b Entrapment of NP inside a RBC, here entrapped RBC ca be release NP with the help of diffusion or substrate activation (a)

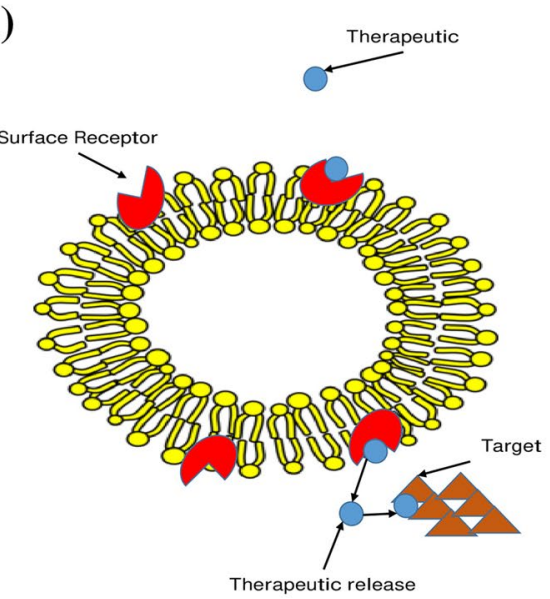

(b) XTherapeutic 1 (Release by diffusion) $\checkmark$ Therapeutic 2 (Release with substrate)

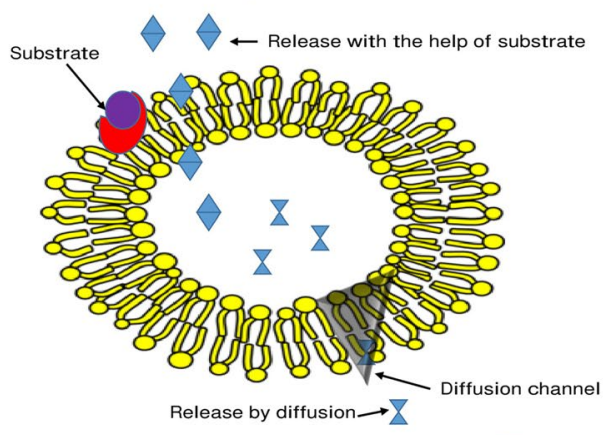

$\bar{x}$ against phagocytic clearance (Kumar et al. 2019). This is achieved by modifying the outer membrane proteins with poly (lactic-co-glycolic acid) followed by coating with inorganic AuNP (Hu et al. 2011). CD 47 is the self-marker identified on RBCs surface that signals macrophages and prevents their uptake (Tsai et al. 2010). C8-binding protein (C8 bp), homologous restriction protein (HRP), decay accelerating factor (DAF), membrane cofactor protein (MCP), complement receptor 1 (CR1), and CD59 are the other membrane proteins present on RBCs which resist the attack by the complement system (Schönermark et al. 1988). Therefore, AuNPs-RBC confer immunosuppression for avoiding macrophage uptake.

\section{RBC-NPs based nanosponges}

RBC-NP have been developed as toxin nanosponges to neutralize the pore-forming toxins (PFTs). The toxins are absorbed by an inner polymeric core of RBCs which stabilize the shell that allow long-term systemic circulation 
(Hu et al. 2013a). The shell locks the toxin from bioactivity and keeps it away from the cellular target. In vivo studies on mouse model have shown to reduce the toxicity of $\alpha$-haemolysin of staphylococcus and increased the lifespan of the challenged mouse (Jacobson et al. 1997). Such RBCs-NP have a promising approach against chemical and biological molecules. Thus, RBCs-NP-based vaccines are developed against membrane active protein toxins. Two successful neutralizations using small peptide from bee venom and oligomerizing streptolysin-O from Streptococcus bacteria have been reported (Hu et al. 2013b). It is a promising platform against infectious diseases for vaccine development.

\section{RBC based iron oxide nanocarrier}

Iron NPs posses paramagnetic magnetic effect with the properties like chemical inertness, minimum toxicity, compatibility with a biological system, catalytic efficiency and availability for surface modification which allow it to be widely used in applications like targeted drug delivery, imaging using MRI and biosensing (glucose and cholesterol detection) (Vallabani et al. 2017; Turcheniuk et al. 2013; Vallabani and Singh 2018; Hossen et al. 2018). Modification of RBCs surface with particles having magnetic and fluorescent properties have long circulating time as proposed by Laurencin et al. (2013). Core-shell magnetic NPs are obtained with citrated magnetic NPs embedded in silica gel (CSMN). The cell specificity is increased by the negative charge of RBCs along with PEG chains that limit the haemolytic activity and positively charged amino group of CSMNs. Fluorescent molecules like fluorescein and rhodamine can be integrated into the silica shell for microscopic applications (Mai et al. 2013). Such magnetic NP loaded on RBCs help in diagnosis through MRI imaging and therapeutic uses. Ferro fluids entrapped in RBCs have been studied in vitro for drug delivery on the site of action such as ibuprofen-loaded and diclofenac sodium-loaded erythrocytes which are magnetically responsive (Jain and Vyas 1994). Magnetic RBCs can be employed for 3D visualization of real-time vessels, monitoring of bleeding during stroke and controlled treatment of cardiovascular diseases (Antonelli and Magnani 2014).

\section{Toxicity of nanoparticles}

NP show great potential as the therapeutic agent and due to their large surface area, they are considered as an efficient mode in drug delivery system. Interactions with the biological components give rise to undesirable toxicity causing mortality of the healthy cells. Cellular uptake of NPs depends on the type of dose administered, but RBCs being the key player in immunological system generate a response to encounter any of these foreign particles entering the system. To formulate NP-based drug carriers it is vital to elucidate various toxicity mechanisms and pave paths to reduce them. There are two major types of effect contributing to toxicity index such as cytotoxicity and genotoxicity.

\section{Cytotoxicity}

The toxic effects shown by the cells are function of dose (Fonseca et al. 2017), time of exposure (Qualhato et al. 2017), size (Zhang et al. 2011; Kwon et al. 2012) surface charge (Zhao et al. 2011), particulate state (Liao et al. 2011) and additionally route of administration (Shrivastava et al. 2014 ) if it is a in vivo model.

Erythrocytes when treated with NPs show cytotoxic effects like morphological changes in the cells, increased oxidative stress and inflammatory response leading to acute or chronic levels of toxicity (Baranwal et al. 2018). In RBC sedimentation rate, hemolysis, abnormal morphology and agglutination seems to be interrelated, as when the nanoparticle attaches to the membrane of a cell it changes the native properties of membrane-like symmetry by rearrangement of lipids across the two leaflets leading to its disintegration and change in cellular shape which enhances the rate of sedimentation and finally resulting in hemolysis of the cell as seen in case of nano- $\mathrm{TiO}_{2}$ ( $\mathrm{Li}$ et al. 2008), nC60THF (Trpkovic et al. 2010), AgNPs (Osborne et al. 2015), AuNPs (Shrivastava et al. 2016), PtNPs (Asharani et al. 2010), dendrimer curcumin nano-formulation (Yallapu et al. 2011). After the hemolysis has occurred, there is significant amount of $\mathrm{Hb}$ released which maintains weak interactions with the NPs and interact with it as shown by change in the spectra of $\mathrm{Hb}$ (Ghosh et al. 2013). A variable amount of toxicity is caused by different type of NPs which suggest that physiochemical properties like shape, size, surface functional groups essentially influences the intensity of toxicity caused (Turkez et al. 2014).

Normally erythrocytes are discocytic in shape, but concentration dependent morphological changes are observed in which higher concentration of $\mathrm{TiO}_{2}$ forms echinocyte, whereas lower concentration leads to spherocytic shaped erythrocyte. The crystalline state of NPs also contribute to variation in toxicity instigated, in case of silica NP mesoporous silica NP are more toxic than nonporous silica NP. This is confirmed by hemolytic studies on erythrocytes (Lin and Haynes 2010) and a parallel study on silver shows that AgNP do not induce haemolysis in the same concentration of silver nanowires causes hemolytic breakage of erythrocyte (Kim and Shin 2014).

Similarly surface charge and functional group present determine the extent of damage to the cell, in a study of RBCs and Cos- 1 cells having constant sized NP of $2 \mathrm{~nm}$ with cationic and anionic charge shows difference in toxicity. The

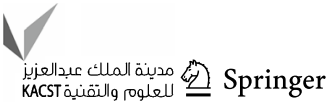


cationic particle is moderately toxic but the anionic particle is nontoxic, though toxicity is in distinguishable between the two cell types (Goodman et al. 2004). Graphene oxide and mesoporous silica comprise of surface charge which also determines the extent of destruction caused at morphological level, in case of RBCs their membrane interact and establish electrostatic interactions with the negatively charged functional groups such hydroxyl and carboxylic acid species. So quenching these minimizes the intensity of attractive forces acting thereby decreasing the toxicity caused (Fonseca et al. 2017). Amine-terminated silicon nanoparticles (SiNP$\mathrm{NH} 2$ ) and carboxylic acid terminated silicon nanoparticles (SiNP-COOH), are positively and negatively charged derivative of silicon nanoparticle, respectively, and both showed differential toxicity when exposed to NR8383 cells which clearly indicates role of surface charge on toxicity posed (Bhattacharjee et al. 2010). Surface modification done for improving drug like properties of a nano-formulation should also be considered as polyethylene glycol-functionalized gold nanoparticles (PEGylated AuNP) bring about changes in normal functioning of erythrocytes indicated by elevated CD47 and aggregation of band 3 (He et al. 2014b). A study by Schaeublin et al. (2011) suggests that both type of surface charges carrying NPs show toxicity towards cell and have capability to redistribute mitochondrial membrane potential finally generating oxidative stress.

Oxidative stress is an imbalance caused between amounts of oxidants, i.e., reactive oxygen species (ROS) and body's inability to encounter them by producing antioxidants (Aggarwal et al. 2017). Generation of ROS is a normal phenomenon but aggravated response is achieved upon passage of toxic compounds in the body (Maurya et al. 2015). Toxicological profile of a NPs is well reflected by amount of oxidative stress it causes in a cell. Uptake of NPs lead to activation of immune cells to combat the adverse effects by generating appropriate inflammatory response via macrophages, monocytes, neutrophils, etc., which releases various cytokines (IL-6, IL-8). They lead to oxidative burst, engorgement of intracellular reactive oxygen species like superoxide ion, hydroxyl radical, singlet oxygen, etc. Metallic NPs are widely employed in commercial products, so extensive studies have been carried out to know the underlying mechanism responsible for oxidative stress-mediated toxicity (Baranwal et al. 2016). Range of biomarkers are available to assess level of oxidative stress in a cell (Maurya et al. 2015, 2016b; Kumar et al. 2016; Maurya and Chandra 2017). These biomarkers are found to be elevated in a cell which is exposed to toxic concentration range of NPs. Upon cellular uptake of NPs they are phagocytosed by erythrocytes, followed by attachment to its membrane which immediately leads to oxidation of the lipids and activity of the antioxidant enzyme (Mahato et al. 2016). The catalase is altered making this enzyme functionally inefficient rendering toxicity as in case of $\mathrm{TiO}_{2}, \mathrm{ZnO}$ and $\mathrm{Al}_{2} \mathrm{O}_{3}$ in a male mice with concentration of $500 \mathrm{mg} / \mathrm{kg}$ for 21 days (Shrivastava et al. 2014). Oxidative stress is also concentration dependent phenomenon (Bacchetta et al. 2017). Amorphous SiNPs incubated with erythrocytes lead to decreased level of GSH and SOD while increased lipid peroxidation (LPO) (Nemmar et al. 2014). Nanohydroxyapatite NPs in a human blood culture showed increased amount of lactate dehydrogenase (LDH) which is another indicator of oxidative injury (Turkez et al. 2014). Supportive studies have been done on other NPs like AuNP (Shrivastava et al. 2016), $\mathrm{Fe}_{3} \mathrm{O}_{4}$ (Srinivas et al. 2012) and AgNP (Shrivastava et al. 2016). Furthermore, it has been shown by some studies that aggregation of IONP take place in the system where they tend to adhere to the cell surface and this iron overload could induce toxic effects and an imbalance in the homeostasis (Zhu et al. 2012). Oxidative stress is also affected by BET surface and internalized amount of NPs (Hussain et al. 2009). On oral gavage of nickel oxide (NiO) NPs, Wistar rats showed acute toxicity by inhibiting RBCsv (Hussain et al. 2009). Rarely any study has reported about evolving ROS which is another source for oxidative stress.

\section{Genotoxicity}

Genotoxicity reveals the response of genetic material when cells are exposed to NPs. Abrupt changes occurring at DNA level deterrent normal behavior of a cell in terms of its function and ultimately induces apoptosis or necrosis type of cell death. Small size of NPs make it an effective agent which can easily trespass the nuclear membrane barrier making an entry through nuclear pores and then directly interacting with DNA or central dogma proteins causing DNA fragmentation or damage (Prasad et al. 2016). NPs can cause genotoxicity which is evaluated by formation of single or double stranded breaks, micronuclei formation, generation of array of deletions in DNA sequence, DNA adduct formation and chromosomal aberrations. Few studies have been done on this parameter like $\mathrm{TiO}_{2}$ damages DNA by oxidation of both the nitrogenous bases, i.e., pyrimidine and purine at a concentration of $4 \mathrm{ug} / \mathrm{ml}$ in trout which alarms the extinction of aquatic life (Sekar et al. 2014). In vivo effect of $\mathrm{TiO}_{2}$ on mice showed not only transient single stranded breaks but also double stranded breaks evident by generation of $\gamma$-H2AX foci (Trouiller et al. 2009). Not only direct incubation with erythrocytes cause toxicity, but also when given by ad libitum to a fish called $P$. reticulata cause significant DNA damage starting from incubation time of 3 days up to 14 days in an accelerating pattern (Qualhato et al. 2017). Micronuclei assay determines the cytogenetic deformities and genotoxic potential of NP in which long-term exposure causes more of the micronuclei when compared to 
short-term exposure as investigated in in vivo studies (Xia et al. 2017).

Coupling of cytotoxic and genotoxic effects bring cell to its final fate, i.e., death. Either apoptosis or necrosis has been reported by various research investigators but in case of RBCs it is most commonly referred to as erythroptosis. When NPs are coated with biocompatible polymers like polyethylene glycol (PEG) they show decrease in the number of cells undergoing apoptotic pathway as compared to the bare NPs or chemical coating, this has been reported in case of CTAB-AuNP versus PEG-coated AuNP (Lau et al. 2012) in human RBCs. Spherical shaped $25 \mathrm{~nm}$ AuNP in initial concentration range did not show significant apoptotic effects but result showed that AuNP concentration when reached $200 \mu \mathrm{g} / \mathrm{mL}$ induced apoptotic effects like cell shrinkage, cell surface blabbing, mitochondria damage and disturbance in electron transfer in mitochondrial membranes and cytochrome c, and oxidative stress (Miri et al. 2018). Preferential death by apoptosis was observed in this study and after extending incubation time beyond $24 \mathrm{~h}$ apoptotic cell followed secondary necrosis (Nirmala et al. 2017).

\section{Challenges and opportunities}

After extensive preclinical studies, this technique has entered into the clinical stage of drug development process which alarms certain challenges accompanied by it. Designing and fabrication of RBCs based NP drug carrier system need to maintain some boundary conditions which accomplish its role as a therapeutic agent. This involves limiting surface modification of RBCs to a threshold value which does not confer any immunogenic reaction or rejection along with a prolonged survival of this carrier system in circulatory system. Generation of RBC-NP drug system employ two common techniques either drug attachment by adsorption or by encapsulation of drug in a RBCs membrane. In case of encapsulation crosslinking methodology is adopted which damage RBCs membrane leading to its deformation. Any subtle deviation from the desired modification can alter RBCs surface in a way that it loses its ability to inhibit complement system or engulfment by phagocytes and even reacting with unwanted targets or components of circulatory system making a rapid exit in vivo studies, while in case of physical adsorption nonspecific (weak) interactions are established between the NPs and RBC membrane components which minimizes hemolytic reaction against these modified RBC system, some parallel studies which support usage of biocompatible carrier have shown minimisation of haemolysis by using BSA as-coating agent when compared to independent NPs (Purohit et al. 2016). Adherence of NPs to RBCs alter its pharmacokinetic properties, distribution among organs and function to some extent which raises toxic effects which later manifested into hypoxia and thrombosis. Using RBCs as a carrier system require proper storage conditions to retain its fully functional form. When this nano-formulation is given to a recipient, immunogenic compatibility should be maintained which ensures its efficacy and safety as a drug. In case of direct hybridization of NPs to RBCs can make undesired modification capable of forming a non-biocompatible drug which makes host immune system active and subsequently eliminating drug from the body without any profound action. Recent advances bring RBC hitchhiking, RBC cloaking and RBC hybrids as major noncarrier making all of the more biogenic in nature so that constituents shifts from non-self to self-components and elicit a neglected immune response making it nontoxic. With additional usage of more blood-based and cell-based elements, it makes this technique more sophisticated and costly. Food and Drug Administration (FDA) the regulatory body for drug administration involves additional steps for these kinds of drugs governed by various intra-functioning bodies which lay different rules and guidelines for investigation and marketing of biological therapeutics thus increasing overall procedural complexity. Co-existence of advantages and limitations make this system perfectly viable, but window for improvement always exist so that these therapies can take a lead from preclinical stage to clinical stage and finally in the market as an efficient treatment for endemic diseases.

\section{Conclusion}

With this review, we conclude that RBCs act as a good model for NPs and drug delivery system. NPs and their characteristic affect various components of RBCs and its membrane. Some in vitro studies have suggested that method of fabrication, surface properties, shape and size of iron NP possessing paramagnetic effects not only affect RBCs shape but also loading agent and particle used for dispersion. Targeted delivery system of RBC conjugated with NP is a difficult task due to inability of RBCs to move across physiological barriers to penetrate different tissue sites and uptake by different cell types. So there is need to consider all the designing aspects in terms of RBCs spectrum of action. Regulated delivery involves use of paramagnetic nanomaterial so that external applied magnetic field can drive it into the target organs, which has applications in therapeutics and diagnosis synergistically called as theranostics. Fabrication of RBCs as nanocarriers has a promising future in medical science and also in the treatment of various blood associated disorders.

\section{Compliance with ethical standards}

Conflict of interest Authors declare that there is no conflict of interest.

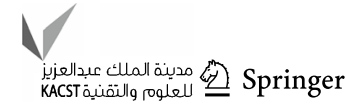




\section{References}

Ademiloye AS, Zhang L, Liew K (2016) Predicting the elastic properties and deformability of red blood cell membrane using an atomistic-continuum approach. In: Proceedings of the international multiconference of engineers and computer scientists 2016, IMECS 2016

Aggarwal T, Wadhwa R, Rohil V, Maurya PK (2017) Biomarkers of oxidative stress and protein-protein interaction in chronic obstructive pulmonary disease. Arch Phys Biochem 124(3):226-231

Agnihotri J, Saraf S, Singh S, Bigoniya P (2015) Development and evaluation of anti-malarial bio-conjugates: artesunate-loaded nanoerythrosomes. Drug Deliv Transl Res 5(5):489-497

Anselmo AC, Gupta V, Zern BJ, Pan D, Zakrewsky M, Muzykantov V, Mitragotri S (2013) Delivering nanoparticles to lungs while avoiding liver and spleen through adsorption on red blood cells. ACS Nano 7(12):11129-11137

Antonelli A, Magnani M (2014) Red blood cells as carriers of iron oxide-based contrast agents for diagnostic applications. J Biomed Nanotechnol 10(9):1732-1750

Antonelli A, Sfara C, Manuali E, Bruce IJ, Magnani M (2011) Encapsulation of superparamagnetic nanoparticles into red blood cells as new carriers of MRI contrast agents. Nanomedicine 6(2):211-223

Aryal S, Hu C-MJ, Fang RH, Dehaini D, Carpenter C, Zhang D-E, Zhang L (2013) Erythrocyte membrane-cloaked polymeric nanoparticles for controlled drug loading and release. Nanomedicine 8(8):1271-1280

Asharani P, Sethu S, Vadukumpully S, Zhong S, Lim CT, Hande MP, Valiyaveettil S (2010) Investigations on the structural damage in human erythrocytes exposed to silver, gold, and platinum nanoparticles. Adv Func Mater 20(8):1233-1242

Bacchetta C, Ale A, Simoniello MF, Gervasio S, Davico C, Rossi AS, Desimone MF, Poletta G, López G, Monserrat JM (2017) Genotoxicity and oxidative stress in fish after a short-term exposure to silver nanoparticles. Ecol Ind 76:230-239

Baranwal A, Mahato K, Srivastava A, Maurya PK, Chandra P (2016) Phytofabricated metallic nanoparticles and their clinical applications. RSC Adv 6(107):105996-106010

Baranwal A, Srivastava A, Kumar P, Bajpai VK, Maurya PK, Chandra P (2018) Prospects of nanostructure materials and their composites as antimicrobial agents. Front Microbiol 9:422

Bhagat S, Vallabani NS, Shutthanandan V, Bowden M, Karakoti AS, Singh S (2018) Gold core/ceria shell-based redox active nanozyme mimicking the biological multienzyme complex phenomenon. J Colloid Interface Sci 513:831-842

Bhattacharjee S, de Haan LH, Evers NM, Jiang X, Marcelis AT, Zuilhof H, Rietjens IM, Alink GM (2010) Role of surface charge and oxidative stress in cytotoxicity of organic monolayer-coated silicon nanoparticles towards macrophage NR8383 cells. Part Fibre Toxicol 7(1):25

Bransky A, Korin N, Nemirovski Y, Dinnar U (2006) An automated cell analysis sensing system based on a microfabricated rheoscope for the study of red blood cells physiology. Biosens Bioelectron 22(2):165-169

Chambers E, Mitragotri S (2004) Prolonged circulation of large polymeric nanoparticles by non-covalent adsorption on erythrocytes. J Control Release 100(1):111-119

Chen K, Merkel TJ, Pandya A, Napier ME, Luft JC, Daniel W, Sheiko S, DeSimone JM (2012) Low modulus biomimetic microgel particles with high loading of hemoglobin. Biomacromol 13(9):2748-2759

Chen K, Xu J, Luft JC, Tian S, Raval JS, DeSimone JM (2014) Design of asymmetric particles containing a charged interior and a neutral surface charge: comparative study on in vivo circulation of polyelectrolyte microgels. J Am Chem Soc 136(28):9947-9952

Davson H, Danielli JF (1943) The permeability of natural membranes. Cambridge University Press, Cambridge

Deng J, Xu S, Hu W, Xun X, Zheng L, Su M (2018) Tumor targeted, stealthy and degradable bismuth nanoparticles for enhanced $\mathrm{X}$-ray radiation therapy of breast cancer. Biomaterials 154:24-33

Désilets J, Lejeune A, Mercer J, Gicquaud C (2001) Nanoerythrosomes, a new derivative of erythrocyte ghost: IV. Fate of reinjected nanoerythrosomes. Anticancer Res 21(3B):1741-1747

Doshi N, Zahr AS, Bhaskar S, Lahann J, Mitragotri S (2009) Red blood cell-mimicking synthetic biomaterial particles. Proc Natl Acad Sci 106(51):21495-21499

Dreaden EC, Alkilany AM, Huang X, Murphy CJ, El-Sayed MA (2012) The golden age: gold nanoparticles for biomedicine. Chem Soc Rev 41(7):2740-2779

Fonseca LC, de Araújo MM, de Moraes ACM, da Silva DS, Ferreira AG, Franqui LS, Martinez DST, Alves OL (2017) Nanocomposites based on graphene oxide and mesoporous silica nanoparticles: preparation, characterization and nanobiointeractions with red blood cells and human plasma proteins. Appl Surf Sci 437:110-121

Ghosh M, Chakraborty A, Mukherjee A (2013) Cytotoxic, genotoxic and the hemolytic effect of titanium dioxide $\left(\mathrm{TiO}_{2}\right)$ nanoparticles on human erythrocyte and lymphocyte cells in vitro. J Appl Toxicol 33(10): 1097-1110

Glodek AM, Mirchev R, Golan DE, Khoory JA, Burns JM, Shevkoplyas SS, Nicholson-Weller A, Ghiran IC (2010) Ligation of complement receptor 1 increases erythrocyte membrane deformability. Blood 116(26):6063-6071

Goodman CM, McCusker CD, Yilmaz T, Rotello VM (2004) Toxicity of gold nanoparticles functionalized with cationic and anionic side chains. Bioconjug Chem 15(4):897-900

Gorter E, Grendel F (1925) On bimolecular layers of lipoids on the chromocytes of the blood. J Exp Med 41(4):439-443

He H, Ye J, Wang Y, Liu Q, Chung HS, Kwon YM, Shin MC, Lee K, Yang VC (2014a) Cell-penetrating peptides meditated encapsulation of protein therapeutics into intact red blood cells and its application. J Controlled Release 176:123-132

He Z, Liu J, Du L (2014b) The unexpected effect of PEGylated gold nanoparticles on the primary function of erythrocytes. Nanoscale 6(15):9017-9024

Hossen S, Hossain MK, Basher M, Mia M, Rahman M, Uddin MJ (2018) Smart nanocarrier-based drug delivery systems for cancer therapy and toxicity studies: a review. J Adv Res 15:1-18

Hu C-MJ, Zhang L, Aryal S, Cheung C, Fang RH, Zhang L (2011) Erythrocyte membrane-camouflaged polymeric nanoparticles as a biomimetic delivery platform. Proc Natl Acad Sci 108(27):10980-10985

Hu CMJ, Fang RH, Zhang L (2012) Erythrocyte-inspired delivery systems. Adv Healthc Mater 1(5):537-547

Hu C-MJ, Fang RH, Copp J, Luk BT, Zhang L (2013a) A biomimetic nanosponge that absorbs pore-forming toxins. Nat Nanotechnol $8(5): 336$

Hu C-MJ, Fang RH, Luk BT, Zhang L (2013b) Nanoparticle-detained toxins for safe and effective vaccination. Nat Nanotechnol 8(12):933

Hussain S, Boland S, Baeza-Squiban A, Hamel R, Thomassen LC, Martens JA, Billon-Galland MA, Fleury-Feith J, Moisan F, Pairon J-C (2009) Oxidative stress and proinflammatory effects of carbon black and titanium dioxide nanoparticles: role of particle surface area and internalized amount. Toxicology 260(1-3):142-149

Jacobson DL, Gange SJ, Rose NR, Graham NM (1997) Epidemiology and estimated population burden of selected autoimmune 
diseases in the United States. Clin Immunol Immunopathol 84(3):223-243

Jain S, Vyas S (1994) Magnetically responsive diclofenac sodiumloaded erythrocytes: preparation and in vitro characterization. J Microencapsul 11(2):141-151

Jiang A, Song B, Ji X, Peng F, Wang H, Su Y, He Y (2018a) Doxorubicin-loaded silicon nanoparticles impregnated into red blood cells featuring bright fluorescence, strong photostability, and lengthened blood residency. Nano Res 11(4):2285-2294

Jiang T, Zhang B, Zhang L, Wu X, Li H, Shen S, Luo Z, Liu X, Hu Y, Pang Z (2018b) Biomimetic nanoparticles delivered hedgehog pathway inhibitor to modify tumour microenvironment and improved chemotherapy for pancreatic carcinoma. Artif Cells Nanomed Biotechnol 46(sup1):1088-1101

Kim MJ, Shin S (2014) Toxic effects of silver nanoparticles and nanowires on erythrocyte rheology. Food Chem Toxicol 67:80-86

Kim ER, Fan S, Akhmedov D, Sun K, Lim H, O'Brien W, Xu Y, Mangieri LR, Zhu Y, Lee C-C (2017) Red blood cell $\beta$-adrenergic receptors contribute to diet-induced energy expenditure by increasing O2 supply. JCI Insight 2(14):e93367

Komin A, Russell L, Hristova K, Searson P (2017) Peptide-based strategies for enhanced cell uptake, transcellular transport, and circulation: mechanisms and challenges. Adv Drug Deliv Rev 110:52-64

Kroll AV, Fang RH, Zhang L (2016) Biointerfacing and applications of cell membrane-coated nanoparticles. Bioconjug Chem 28(1):23-32

Kumar P, Maurya PK (2014) Epigallocatechin-3-gallate protects erythrocyte $\mathrm{Ca} 2+-$ ATPase and $\mathrm{Na}+\mathrm{K}+$-ATPase against oxidative induced damage during aging in humans. Adv Pharm Bull 4(Suppl 1):443

Kumar P, Chaudhary N, Sharma NK, Maurya PK (2016) Detection of oxidative stress biomarkers in myricetin treated red blood cells. RSC Adv 6(102):100028-100034

Kumar P, Wadhwa R, Gupta R, Chandra P, Maurya PK (2018) Spectroscopic determination of intracellular quercetin uptake using erythrocyte model and its implications in human aging. 3 Biotech 8(12):498

Kumar V, Wadhwa R, Kumar N, Maurya PK (2019) A comparative study of chemically synthesized and Camellia sinensis leaf extract-mediated silver nanoparticles. 3 Biotech 9(1):7

Kwon T, Woo HJ, Kim YH, Lee HJ, Park KH, Park S, Youn B (2012) Optimizing hemocompatibility of surfactant-coated silver nanoparticles in human erythrocytes. J Nanosci Nanotechnol 12(8):6168-6175

Lau IP, Chen H, Wang J, Ong HC, Leung KC-F, Ho HP, Kong SK (2012) In vitro effect of CTAB-and PEG-coated gold nanorods on the induction of eryptosis/erythroptosis in human erythrocytes. Nanotoxicology 6(8):847-856

Laurencin M, Cam N, Georgelin T, Clément O, Autret G, Siaugue JM, Ménager C (2013) Human erythrocytes covered with magnetic core-shell nanoparticles for multimodal imaging. Adv Healthc Mater 2(9):1209-1212

Lejeune A, Moorjani M, Gicquaud C, Lacroix J (1994) Nanoerythrosome, a new derivative of erythrocyte ghost: preparation and antineoplastic potential as drug carrier for. Anticancer Res 14(915.920):915-920

Li S-Q, Zhu R-R, Zhu H, Xue M, Sun X-Y, Yao S-D, Wang S-L (2008) Nanotoxicity of $\mathrm{TiO}_{2}$ nanoparticles to erythrocyte in vitro. Food Chem Toxicol 46(12):3626-3631

Liao K-H, Lin Y-S, Macosko CW, Haynes CL (2011) Cytotoxicity of graphene oxide and graphene in human erythrocytes and skin fibroblasts. ACS Appl Mater Interfaces 3(7):2607-2615

Lin Y-S, Haynes CL (2010) Impacts of mesoporous silica nanoparticle size, pore ordering, and pore integrity on hemolytic activity. $\mathrm{J}$ Am Chem Soc 132(13):4834-4842
Luk BT, Hu C-MJ, Fang RH, Dehaini D, Carpenter C, Gao W, Zhang L (2014) Interfacial interactions between natural RBC membranes and synthetic polymeric nanoparticles. Nanoscale 6(5):2730-2737

Luk BT, Fang RH, Hu C-MJ, Copp JA, Thamphiwatana S, Dehaini D, Gao W, Zhang K, Li S, Zhang L (2016) Safe and immunocompatible nanocarriers cloaked in RBC membranes for drug delivery to treat solid tumors. Theranostics 6(7):1004

Magnani M, Fazi A, Mangani F, Rossi L, Mancini U (1993) Methanol detoxification by enzyme-loaded erythrocytes. Biotechnol Appl Biochem 18(3):217-226

Mahato K, Baranwal A, Srivastava A, Maurya PK, Chandra P (2016) Smart materials for biosensing applications. In: Techno-Societal 2016, international conference on advanced technologies for societal applications, 2016. Springer, pp 421-431

Mai TD, d'Orlyé F, Ménager C, Varenne A, Siaugue J-M (2013) Red blood cells decorated with functionalized core-shell magnetic nanoparticles: elucidation of the adsorption mechanism. Chem Commun 49(47):5393-5395

Mandal B, Bhattacharjee H, Mittal N, Sah H, Balabathula P, Thoma LA, Wood GC (2013) Core-shell-type lipid-polymer hybrid nanoparticles as a drug delivery platform. Nanomed Nanotechnol Biol Med 9(4):474-491

Maurya PK, Chandra P (2017) Oxidative stress: diagnostic methods and applications in medical science. Springer, Berlin

Maurya PK, Kumar P, Chandra P (2015) Biomarkers of oxidative stress in erythrocytes as a function of human age. World $\mathbf{J}$ Methodol 5(4):216

Maurya PK, Kumar P, Chandra P (2016a) Age-dependent detection of erythrocytes glucose-6-phosphate dehydrogenase and its correlation with oxidative stress. Arch Physiol Biochem 122(2):61-66

Maurya PK, Kumar P, Nagotu S, Chand S, Chandra P (2016b) Multi-target detection of oxidative stress biomarkers in quercetin and myricetin treated human red blood cells. RSC Adv 6(58):53195-53202

Miri A, Darroudi M, Entezari R, Sarani M (2018) Biosynthesis of gold nanoparticles using Prosopis farcta extract and its in vitro toxicity on colon cancer cells. Res Chem Intermed 44(5):3169-3177

Nagavarma B, Yadav HK, Ayaz A, Vasudha L, Shivakumar H (2012) Different techniques for preparation of polymeric nanoparticles-a review. Asian J Pharm Clin Res 5(3):16-23

Nemmar A, Beegam S, Yuvaraju P, Yasin J, Shahin A, Ali BH (2014) Interaction of amorphous silica nanoparticles with erythrocytes in vitro: role of oxidative stress. Cell Physiol Biochem 34(2):255-265

Nirmala JG, Akila S, Narendhirakannan R, Chatterjee S (2017) Vitis vinifera peel polyphenols stabilized gold nanoparticles induce cytotoxicity and apoptotic cell death in A431 skin cancer cell lines. Adv Powder Technol 28(4):1170-1184

Orlov D, Karkouti K (2015) The pathophysiology and consequences of red blood cell storage. Anaesthesia 70(s1):29

Osborne OJ, Lin S, Chang CH, Ji Z, Yu X, Wang X, Lin S, Xia T, Nel AE (2015) Organ-specific and size-dependent Ag nanoparticle toxicity in gills and intestines of adult zebrafish. ACS Nano 9(10):9573-9584

Paglia DE, Valentine WN (1967) Studies on the quantitative and qualitative characterization of erythrocyte glutathione peroxidase. $\mathbf{J}$ Lab Clin Med 70(1):158-169

Pan DC, Myerson JW, Brenner JS, Patel PN, Anselmo AC, Mitragotri S, Muzykantov V (2018) Nanoparticle properties modulate their attachment and effect on carrier red blood cells. Sci Rep $8(1): 1615$

Pei Q, Hu X, Zheng X, Liu S, Li Y, Jing X, Xie Z (2018) Light-activatable red blood cell membrane-camouflaged dimeric prodrug nanoparticles for synergistic photodynamic/chemotherapy. ACS Nano 12(2):1630-1641

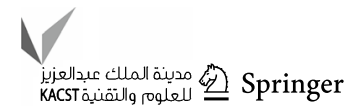


Prasad A, Mahato K, Chandra P, Srivastava A, Joshi SN, Maurya PK (2016) Bioinspired composite materials: applications in diagnostics and therapeutics. J Mol Eng Mater 4(01):1640004

Purohit R, Singh S (2018) Fluorescent gold nanoclusters for efficient cancer cell targeting. Int J Nanomed 13:15

Purohit R, Vallabani NS, Shukla RK, Kumar A, Singh S (2016) Effect of gold nanoparticle size and surface coating on human red blood cells. Bioinspired Biomim Nanobiomaterials 5(3):121-131

Qualhato G, Rocha TL, de Oliveira Lima EC, e Silva DM, Cardoso JR, Grisolia CK, de Sabóia-Morais SMT (2017) Genotoxic and mutagenic assessment of iron oxide (maghemite- $\gamma$-Fe2O3) nanoparticle in the guppy Poecilia reticulata. Chemosphere 183:305-314

Rao L, Cai B, Bu L-L, Liao Q-Q, Guo S-S, Zhao X-Z, Dong W-F, Liu W (2017) Microfluidic electroporation-facilitated synthesis of erythrocyte membrane-coated magnetic nanoparticles for enhanced imaging-guided cancer therapy. ACS Nano 11(4):3496-3505

Ren H, Liu J, Li Y, Wang H, Ge S, Yuan A, Hu Y, Wu J (2017) Oxygen self-enriched nanoparticles functionalized with erythrocyte membranes for long circulation and enhanced phototherapy. Acta Biomater 59:269-282

Rizvi SI, Maurya PK (2007) Markers of oxidative stress in erythrocytes during aging in humans. Ann N Y Acad Sci 1100(1):373-382

Robertson JD (1959) The ultrastructure of cell membranes and their derivatives. In: Biochemical society symposium, p 3

Rossi L, Serafini S, Cenerini L, Picardi F, Bigi L, Panzani I, Magnani M (2001) Erythrocyte-mediated delivery of dexamethasone in patients with chronic obstructive pulmonary disease. Biotechnol Appl Biochem 33(2):85-89

Sahoo K, Karumuri S, Hikkaduwa Koralege RS, Flynn NH, Hartson S, Liu J, Ramsey JD, Kalkan AK, Pope C, Ranjan A (2017) Molecular and biocompatibility characterization of red blood cell membrane targeted and cell-penetrating-peptide-modified polymeric nanoparticles. Mol Pharm 14(7):2224-2235

Schaeublin NM, Braydich-Stolle LK, Schrand AM, Miller JM, Hutchison J, Schlager JJ, Hussain SM (2011) Surface charge of gold nanoparticles mediates mechanism of toxicity. Nanoscale 3(2):410-420

Schönermark S, Filsinger S, Berger B, Hänsch GM (1988) The C8-binding protein of human erythrocytes: interaction with the components of the complement-attack phase. Immunology 63(4):585-590

Sekar D, Falcioni ML, Barucca G, Falcioni G (2014) DNA damage and repair following in vitro exposure to two different forms of titanium dioxide nanoparticles on trout erythrocyte. Environ Toxicol 29(1):117-127

Serafini S, Rossi L, Antonelli A, Fraternale A, Cerasi A, Crinelli R, Chiarantini L, Schiavano G, Magnani M (2004) Drug delivery through phagocytosis of red blood cells. Transfus Med Hemother 31(2):92-101

Shah J, Singh S (2018) Unveiling the role of ATP in amplification of intrinsic peroxidase-like activity of gold nanoparticles. 3 Biotech 8(1):67

Shah J, Purohit R, Singh R, Karakoti AS, Singh S (2015) ATPenhanced peroxidase-like activity of gold nanoparticles. J Colloid Interface Sci 456:100-107

Shrivastava R, Raza S, Yadav A, Kushwaha P, Flora SJ (2014) Effects of sub-acute exposure to $\mathrm{TiO}_{2}, \mathrm{ZnO}$ and $\mathrm{Al}_{2} \mathrm{O}_{3}$ nanoparticles on oxidative stress and histological changes in mouse liver and brain. Drug Chem Toxicol 37(3):336-347

Shrivastava R, Kushwaha P, Bhutia YC, Flora S (2016) Oxidative stress following exposure to silver and gold nanoparticles in mice. Toxicol Ind Health 32(8):1391-1404

Singer SJ, Nicolson GL (1972) The fluid mosaic model of the structure of cell membranes. Science 175(4023):720-731
Singh S (2017) Glucose decorated gold nanoclusters: a membrane potential independent fluorescence probe for rapid identification of cancer cells expressing Glut receptors. Colloids Surf, B 155:25-34

Skalak R, Branemark P (1969) Deformation of red blood cells in capillaries. Science 164(3880):717-719

Srinivas A, Rao PJ, Selvam G, Goparaju A, Murthy BP, Reddy NP (2012) Oxidative stress and inflammatory responses of rat following acute inhalation exposure to iron oxide nanoparticles. Hum Exp Toxicol 31(11):1113-1131

Steck TL (1974) The organization of proteins in the human red blood cell membrane: a review. J Cell Biol 62(1):1

Su J, Sun H, Meng Q, Zhang P, Yin Q, Li Y (2017) Enhanced blood suspensibility and laser-activated tumor-specific drug release of theranostic mesoporous silica nanoparticles by functionalizing with erythrocyte membranes. Theranostics 7(3):523

Sun Y, Su J, Liu G, Chen J, Zhang X, Zhang R, Jiang M, Qiu M (2017) Advances of blood cell-based drug delivery systems. Eur J Pharm Sci 96:115-128

Toumey C (2015) Thank you, Royal Society. Nat Nanotechnol 10(4):291

Trouiller B, Reliene R, Westbrook A, Solaimani P, Schiestl RH (2009) Titanium dioxide nanoparticles induce DNA damage and genetic instability in vivo in mice. Can Res 69(22):8784-8789

Trpkovic A, Todorovic-Markovic B, Kleut D, Misirkic M, Janjetovic K, Vucicevic L, Pantovic A, Jovanovic S, Dramicanin M, Markovic $\mathrm{Z}$ (2010) Oxidative stress-mediated hemolytic activity of solvent exchange-prepared fullerene (C60) nanoparticles. Nanotechnology 21(37):375102

Tsai RK, Rodriguez PL, Discher DE (2010) Self inhibition of phagocytosis: the affinity of 'marker of self' CD47 for SIRP $\alpha$ dictates potency of inhibition but only at low expression levels. Blood Cells Mol Dis 45(1):67-74

Tu J, Bussmann J, Du G, Gao Y, Bouwstra JA, Kros A (2018) Lipid bilayer-coated mesoporous silica nanoparticles carrying bovine hemoglobin towards an erythrocyte mimic. Int J Pharm 543(1-2):169-178

Turcheniuk K, Tarasevych AV, Kukhar VP, Boukherroub R, Szunerits S (2013) Recent advances in surface chemistry strategies for the fabrication of functional iron oxide based magnetic nanoparticles. Nanoscale 5(22):10729-10752

Turkez H, Yousef MI, Sönmez E, Togar B, Bakan F, Sozio P, Stefano AD (2014) Evaluation of cytotoxic, oxidative stress and genotoxic responses of hydroxyapatite nanoparticles on human blood cells. J Appl Toxicol 34(4):373-379

Vallabani NS, Singh S (2018) Recent advances and future prospects of iron oxide nanoparticles in biomedicine and diagnostics. 3 Biotech 8(6):279

Vallabani NS, Karakoti AS, Singh S (2017) ATP-mediated intrinsic peroxidase-like activity of Fe3O4-based nanozyme: one step detection of blood glucose at physiological pH. Colloids Surf, B 153:52-60

Villa CH, Seghatchian J, Muzykantov V (2016) Drug delivery by erythrocytes: "Primum non nocere". Transfus Apheres Sci 55(3):275-280

Wang X, Li H, Liu X, Tian Y, Guo H, Jiang T, Luo Z, Jin K, Kuai X, Liu Y (2017) Enhanced photothermal therapy of biomimetic polypyrrole nanoparticles through improving blood flow perfusion. Biomaterials 143:130-141

Waugh R, Evans E (1979) Thermoelasticity of red blood cell membrane. Biophys J 26(1):115-131

Xia Q, Li H, Liu Y, Zhang S, Feng Q, Xiao K (2017) The effect of particle size on the genotoxicity of gold nanoparticles. J Biomed Mater Res, Part A 105(3):710-719

Xuan M, Shao J, Zhao J, Li Q, Dai L, Li J (2018) Magnetic mesoporous silica nanoparticles cloaked by red blood cell 
membranes: applications in cancer therapy. Angew Chemie Int Ed 57(21):6049-6053

Yallapu MM, Ebeling MC, Chauhan N, Jaggi M, Chauhan SC (2011) Interaction of curcumin nanoformulations with human plasma proteins and erythrocytes. Int J Nanomed 6:2779

Yoo J-W, Irvine DJ, Discher DE, Mitragotri S (2011) Bio-inspired, bioengineered and biomimetic drug delivery carriers. Nat Rev Drug Discovery 10(7):521

Zaitsev S, Kowalska MA, Neyman M, Carnemolla R, Tliba S, Ding B-S, Stonestrom A, Spitzer D, Atkinson JP, Poncz M (2012)
Targeting recombinant thrombomodulin fusion protein to red blood cells provides multifaceted thromboprophylaxis. Blood 119(20):4779-4785

Zhang X-D, Wu D, Shen X, Liu P-X, Yang N, Zhao B, Zhang H, Sun Y-M, Zhang L-A, Fan F-Y (2011) Size-dependent in vivo toxicity of PEG-coated gold nanoparticles. Int J Nanomed 6:2071

Zhao Y, Sun X, Zhang G, Trewyn BG, Slowing II, Lin VS-Y (2011) Interaction of mesoporous silica nanoparticles with human red blood cell membranes: size and surface effects. ACS Nano 5(2):1366-1375 